\title{
Electrochemical Sensing of Acyclovir at a Gold Electrode Modified with 2-Mercaptobenzothiazole-[5,10,15,20-tetrakis- (3-methoxy-4-hydroxyphenyl)porphyrinato]copper(II)
}

\author{
Renjini JosEPH and K. Girish KUMAR ${ }^{\dagger}$ \\ Department of Applied Chemistry, Cochin University of Science and Technology, Kochi-682 022, India
}

\begin{abstract}
The electrooxidation of acyclovir (ACV) was studied using a gold electrode (GE) modified with a self-assembled monolayer of 2-mercaptobenzothiazol (MBZ) and [5,10,15,20-tetrakis(3-methoxy-4-hydroxyphenyl)porphyrinato]copper(II) (TMHPP Cu(II)) by square wave voltammetry (SWV). The self-assembled films are stable and showed blocking characteristics towards the faradaic processes such as gold surface oxidation and under potential deposition of copper. The optimized conditions obtained for the MBZ/TMHPP Cu(II)-modified GE were 0.1 M phosphate buffer solution ( $\mathrm{pH} 7.0$ ), square wave frequency of $15 \mathrm{~Hz}$ and square wave amplitude of $25 \mathrm{mV}$. Under these optimum conditions, the resultant peak current increases linearly with the concentration of ACV in the range of $1.0 \times 10^{-3}$ to $1.0 \times$ $10^{-8} \mathrm{M}$ with a detection limit of $1.0 \times 10^{-8} \mathrm{M}$. The MBZ/TMHPP $\mathrm{Cu}$ (II)-modified GE showed good stability and selectivity and it can be used to quantify ACV in pharmaceutical formulations and urine samples.
\end{abstract}

(Received July 27, 2010; Accepted October 9, 2010; Published January 10, 2011)

\section{Introduction}

Acyclovir: 2-amino-9-((2-hydroxyethoxy)methyl)-1H-purin$6(9 H)$-one (ACV) (Fig. 1) is the most commonly used guanine analogue antiviral drug. It is primarily used for the treatment of herpes simplex as well as herpes zoster infections. Moreover it is used in the treatment of primary genital herpes, herpetic encephalitis, and varicella zoster virus (VZV) infections in immunosuppressed patients. It is also efficacious in preventing HSV infections in renal allograft recipients. ${ }^{1}$ Based on the above description, the quantitative determination of ACV has become very important and hence has been widely studied.

In recent years, various methods have been reported for the determination of ACV. These include high performance liquid chromatography, ${ }^{2}$ radioimmunoassay, ${ }^{3,4}$ fluorometry, ${ }^{5}$ spectrophotometry, ${ }^{6}$ high-performance capillary electrophoresis ${ }^{7}$

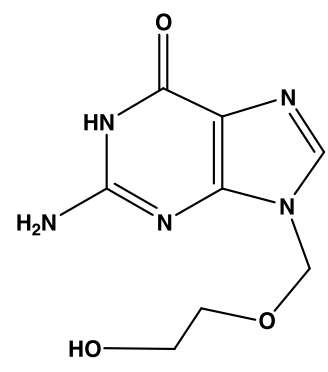

Fig. 1 Structure of acyclovir.

† To whom correspondence should be addressed.

E-mail: giri@cusat.ac.in and chemiluminescence. ${ }^{8}$ But these methods suffer from low sensitivity and narrow linear concentration ranges and some even employ expensive instruments. So we adopt electrochemical methods based on chemically modified electrode (CME), as they are very simple, convenient and inexpensive.

CMEs can be fabricated by using various techniques which include electropolymerization, ${ }^{9}$ dip-dry method, ${ }^{10}$ drop dry method, ${ }^{11}$ vapor deposition, ${ }^{12}$ spin coating, ${ }^{13}$ LangmuirBlodgett ${ }^{14}$ and the self assembled monolayer (SAM) technique. SAM technique is a recently developed technique which is simple and reproducible and the molecules are chemically bound to the electrodes. Notable advantages of SAM over other techniques for electrode modification are the high order and stability of the molecules on electrodes. ${ }^{15,16}$ The chemisorption of thiolates on gold through strong $\mathrm{S}-\mathrm{Au}$ bonds is the most important class of SAM from the electrochemical point of view. By the strong S-Au bonds the thiol molecules are linked to gold electrode surfaces, thus forming SAMs. These modified surfaces exhibit new electrochemical and physical properties that are from the organic monolayer. Apart from this, the application of functionalized SAMs has also been reported. ${ }^{17-19}$

Recently, synthetic metalloporphyrins have attracted attention in relation to the chemical and biological recognition. ${ }^{20,21}$ Electrodes prepared by incorporating metalloporphyrins are good candidates for various applications, because they have excellent thermal, chemical, electrochemical, and photochemical stability. ${ }^{22}$ Synthesis of thiol derivatized metalloporphyrin is tedious and requires toxic chemicals. But there are reports about immobilizing metalloporphyrin to surface confined monolayer of thiol formed on gold electrode (GE). ${ }^{23}$ The advantages of SAM modified GE using different metallophthalocyanine complexes have been reported by Nyokong and coworkers for the determination of several analytes. ${ }^{2428}$ As part of our investigations, we report strategies 


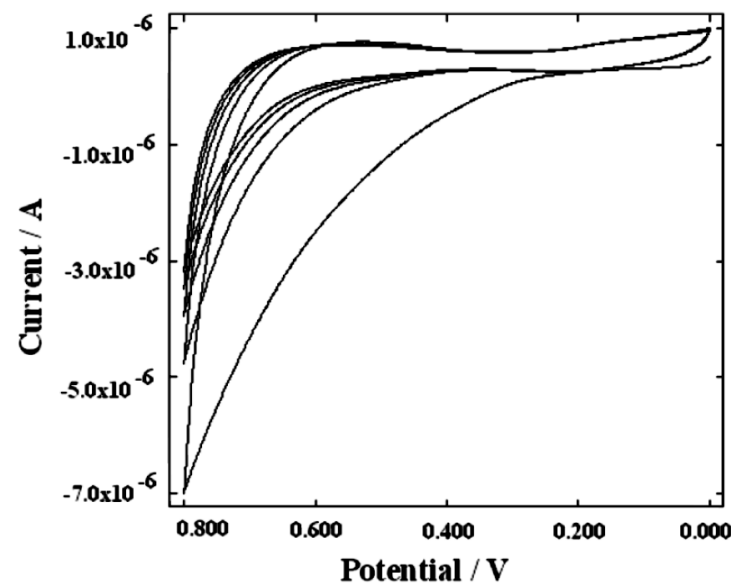

Fig. 2 Cyclic voltammograms for electrode regeneration at MBZ/TMHPP Cu(II)-modified GE in 0.1 M PBS (pH 7).

to link metalloporphyrin, TMHPP $\mathrm{Cu}$ (II) to the MBZ modified GE through adsorption. To the best of our knowledge, no studies on the electrochemical behavior of $\mathrm{ACV}$ and its quantitative determination at MBZ/TMHPP $\mathrm{Cu}$ (II)-modified GE have been reported yet.

\section{Experimental}

\section{Reagents and materials}

All reagents used in this study were of analytical grade and all solutions were prepared with Milli-Q water. Pyrrole and 3-methoxy-4-hydroxy benzaldehyde were purchased from Sisco Research Laboratories Ltd., Mumbai, India and were freshly distilled prior to use. $\mathrm{CuCl}_{2} \cdot 2 \mathrm{H}_{2} \mathrm{O}$ was obtained from s.d fine chemicals Pvt. Ltd., Mumbai, India. MBZ was obtained from Spectrochem. Pvt. Ltd., Mumbai, India. Pure ACV was obtained as a gift sample. The supporting electrolyte used was phosphate buffer solution (PBS), which was prepared by using $\mathrm{NaH}_{2} \mathrm{PO}_{4} \cdot 2 \mathrm{H}_{2} \mathrm{O}$ and $\mathrm{Na}_{2} \mathrm{HPO}_{4}$. The stock solutions of ACV $\left(1 \times 10^{-2} \mathrm{M}\right)$ were prepared in methanol. Standard solutions of the analyte were prepared by suitable dilution of the stock solutions using supporting electrolyte (PBS). ACV tablets were purchased from the local market.

\section{Apparatus}

All electrochemical experiments were performed on an electrochemical analyzer (BAS Epsilon Bioanalytical System, USA), interfaced to a PC. A three electrode system that consists of a MBZ/TMHPP $\mathrm{Cu}$ (II) modified GE as working electrode, an $\mathrm{Ag} / \mathrm{AgCl}$ reference electrode and a platinum wire auxiliary electrode was employed. The $\mathrm{pH}$ measurements were carried out with a Metrohm $\mathrm{pH}$ meter. The UV-Visible spectrum was recorded using a Spectro UV-Visible Double beam UVD-3500 instrument. The FT-IR spectra of the powdered samples were recorded on JASCO 4100 FT IR spectrometer using KBr discs. ${ }^{1} \mathrm{H}$ NMR spectra were recorded using a JEOL GSX 400 NB FT NMR spectrometer. Elemental analysis was performed with a Vario EL III CHNS analyzer. Surface morphological studies were carried out using a scanning electron microscopy (SEM), JOEL 6300 LV instrument.

\section{Synthesis of TMHPP}

The synthesis was performed according to the Alder method. ${ }^{29}$

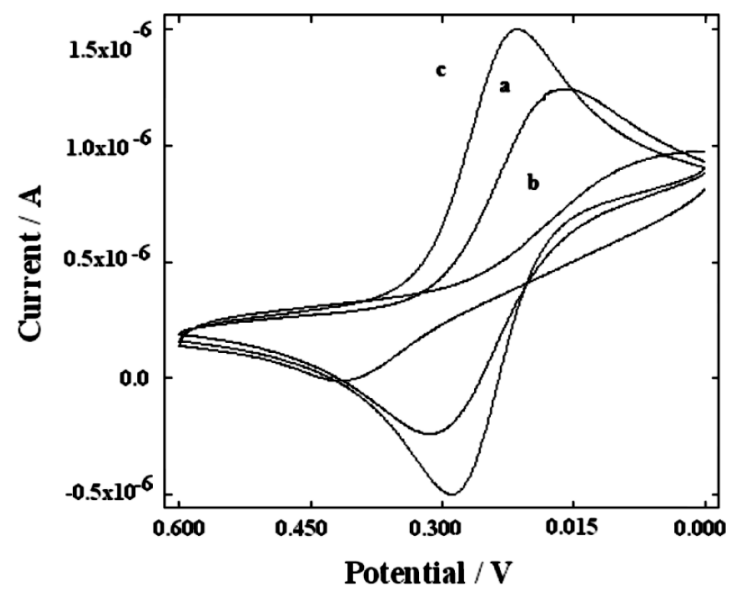

Fig. 3 Cyclic voltammograms of (a) bare GE, (b) MBZ-modified $\mathrm{GE}$, (c) MBZ/TMHPP $\mathrm{Cu}$ (II)-modified GE in $\mathrm{K}_{3} \mathrm{Fe}(\mathrm{CN})_{6}$ solution.

Freshly distilled pyrrole $(1.04 \mathrm{ml}, 0.015 \mathrm{~mol})$ and 3-methoxy4-hydroxy benzaldehyde $(2.282 \mathrm{~g}, 0.015 \mathrm{~mol})$ were added to $30 \mathrm{ml}$ of boiling propionic acid. The mixture was refluxed for $30 \mathrm{~min}$ and was then allowed to cool for a few minutes. The filter cake was washed thoroughly with methanol. The resulting purple crystals were further purified by column chromatography. The yield was found to be $10 \%$. Elemental analysis of the product gave the following results. Calcd. (\%): C, 72.18; $\mathrm{H}$, 4.76; N, 7.01. Found (\%): C, 72.08; H, 4.66; N, 6.97. IR $(\mathrm{KBr}), v\left(\mathrm{~cm}^{-1}\right): 3363(\mathrm{NH}) ; 3000(\mathrm{CH}) ; 3539(\mathrm{OH})$. UV-Visible spectrum in $\mathrm{CH}_{2} \mathrm{Cl}_{2}, \lambda(\mathrm{nm}): 411,445,514,647 .{ }^{1} \mathrm{H} \mathrm{NMR}$ $\left(500 \mathrm{MHz}, \mathrm{CDCl}_{3}\right)$ ppm: $\delta=8.9(\mathrm{~s}, 8 \mathrm{H}$, pyrrollic $-\beta-\mathrm{H}), 5.9$ (s, 4H, OH), 3.9 (s, 12H, OCH3), -2.7 (s, 2H, NH), $8.2-7.3$ (m, 12H, aromatic).

\section{Synthesis of TMHPP Cu(II)}

The ligand TMHPP $(2.5 \mathrm{~g}, 0.003 \mathrm{~mol})$ and $\mathrm{CuCl}_{2} \cdot 2 \mathrm{H}_{2} \mathrm{O}(1.6 \mathrm{~g}$, $0.009 \mathrm{~mol}$ ) were refluxed in $500 \mathrm{ml}$ of $\mathrm{N}, \mathrm{N}$-dimethylformamide for half an hour. The solvent was stripped off and the residue was then extracted into $250 \mathrm{ml}$ water. A red precipitate was formed immediately; it was isolated by filtration, washed with $250 \mathrm{ml}$ of distilled water and air dried. The yield was found to be $4 \%$. Elemental analysis of the product gave the following results. Calcd. (\%): C, 61.43; H, 3.25; N, 6.51. Found (\%): C, 61.20; H, 2.85; N, 6.45. IR (KBr), $v\left(\mathrm{~cm}^{-1}\right): 3363(\mathrm{NH}) ; 3000$ $(\mathrm{CH}) ; 3539(\mathrm{OH}) ; 455(\mathrm{M}-\mathrm{N})$. UV-Visible spectrum in DMSO, $\lambda(\mathrm{nm}): 405,481,530,621$.

\section{Preparation of MBZ/TMHPP Cu(II)-modified GE}

The working GE was mechanically polished with aqueous slurries of alumina $(50 \mathrm{~nm})$ on a flat pad prior to surface modification. After polishing, it was rinsed ultrasonically with absolute ethanol to remove residual alumina particles from the surface and then cleaned with a piranha solution $\left(\mathrm{H}_{2} \mathrm{O}_{2}: \mathrm{H}_{2} \mathrm{SO}_{4}=\right.$ $1: 3, \mathrm{v} / \mathrm{v}$ ) for $10 \mathrm{~min}$. Following this mechanical process, an electrochemical cleaning process was carried out using cyclic voltammetry performed from 0 to $1500 \mathrm{mV}$ in $0.5 \mathrm{M}$ sulfuric acid solution at a scan rate of $100 \mathrm{mV} \mathrm{s}^{-1}$ until a stable cyclic voltammogram was obtained. This procedure avoids structural changes to the gold surface. SAM was formed by immersing the cleaned GE in an ethanolic solution of different monolayer reagents such as MBZ, 1-decane thiol, 3-mercaptopropionic acid and 2-mercaptoethanol. The effect of concentration as well as time for monolayer formation using the above monolayer 


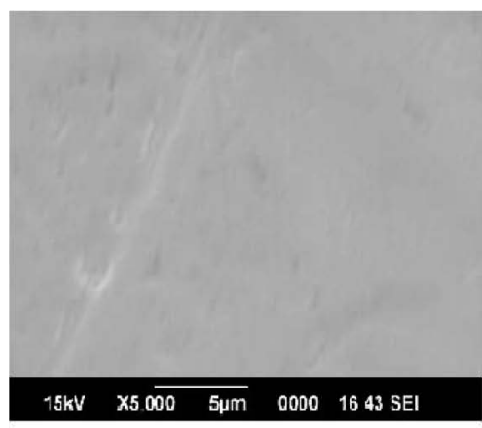

(a)

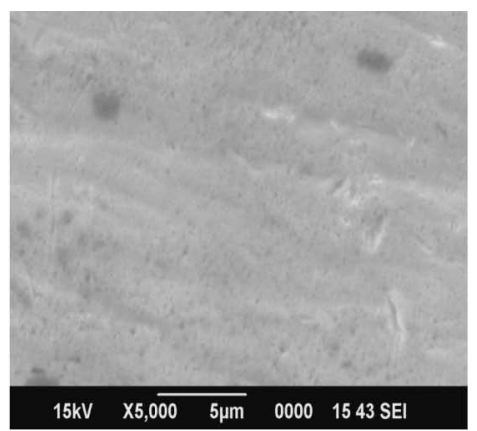

(b)

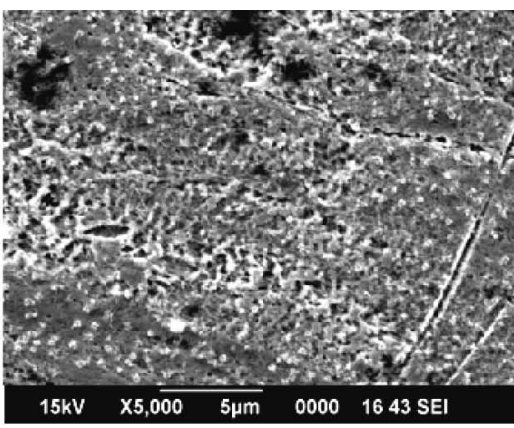

(c)

Fig. 4 SEM images of (a) bare GE, (b) MBZ-modified GE, (c) MBZ/TMHPP Cu(II)-modified GE.

reagents were also studied. But a better voltammetric response was obtained by dipping GE in MBZ $\left(1 \times 10^{-3} \mathrm{M}\right)$ solution for $24 \mathrm{~h}$ at room temperature and by further modification with TMHPP Cu(II). So we selected MBZ as the base monolayer for the attachment of TMHPP $\mathrm{Cu}(\mathrm{II})$. Finally, the MBZ modified electrode was rinsed with ethanol in order to remove the unbonded thiol, and then it was immersed in TMHPP $\mathrm{Cu}(\mathrm{II})$ solution in dimethyl formamide for another period of $24 \mathrm{~h}$.

\section{Analytical procedure}

Stock solutions of ACV $(0.01 \mathrm{M})$ were prepared in methanol. A 10-ml volume of phosphate buffer $(\mathrm{pH} \mathrm{7})$ was taken in the electrochemical cell and the required volume of drug solution was added to it. The solution was then deaerated with nitrogen for $5 \mathrm{~min}$. Square wave voltammetry (SWV) was performed at MBZ/TMHPP $\mathrm{Cu}(\mathrm{II})$-modified $\mathrm{GE}$ and the voltammograms were recorded from 0 to $0.8 \mathrm{~V}$. For electrode regeneration, five cyclic scans were carried out from 0 to $800 \mathrm{mV}$ at a scan rate of $100 \mathrm{mV} \mathrm{s}^{-1}$ in the blank electrolyte solution until a stable voltammogram was obtained (Fig. 2).

\section{Results and Discussion}

\section{Surface study}

Cyclic voltammograms of different electrodes in $\mathrm{K}_{3} \mathrm{Fe}(\mathrm{CN})_{6}$ solution are shown in Fig. 3. $\mathrm{K}_{3} \mathrm{Fe}(\mathrm{CN})_{6}$ exhibits a pair of reversible peaks at bare $\mathrm{GE}\left(\Delta E_{\mathrm{p}}\right.$ is $\left.0.075 \mathrm{~V}\right)$. When it is modified with MBZ, the peaks become almost invisible $\left(\Delta E_{\mathrm{p}}\right.$ is $0.200 \mathrm{~V})$. This is due to the blocking action of MBZ to $\mathrm{K}_{3} \mathrm{Fe}(\mathrm{CN})_{6}$. However, when it is further modified by TMHPP $\mathrm{Cu}(\mathrm{II})$, a pair of reversible peaks occurs $\left(\Delta E_{\mathrm{p}}\right.$ is $\left.0.064 \mathrm{~V}\right)$. Furthermore, the peak currents are much higher than those of bare GE. This may be attributed to the electrostatic interaction between negatively charged $\left[\mathrm{Fe}(\mathrm{CN})_{6}\right]^{3-}$ and $\mathrm{Cu}^{2+}$ redox center of the metalloporphyrin, causing a fast electron transfer which leads to a sharper and better defined peak. The small difference in $\Delta E_{\mathrm{p}}$ value of bare GE and MBZ/TMHPP Cu(II)-modified GE indicates the reversibility of the process.

Then, 2-mM K${ }_{3} \mathrm{Fe}(\mathrm{CN})_{6}$ was taken to measure the microscopic areas of the MBZ/TMHPP $\mathrm{Cu}(\mathrm{II})$-modified GE and bare GE. Cyclic voltammograms were recorded at different scan rates. For a reversible system, the relationship between the current and scan rate is given by the Randles-Sevick equation: ${ }^{30}$

$$
I_{\mathrm{p}}=2.69 \times 10^{5} \mathrm{An}^{3 / 2} \mathrm{Dr}^{1 / 2} \mathrm{C} v^{1 / 2}
$$

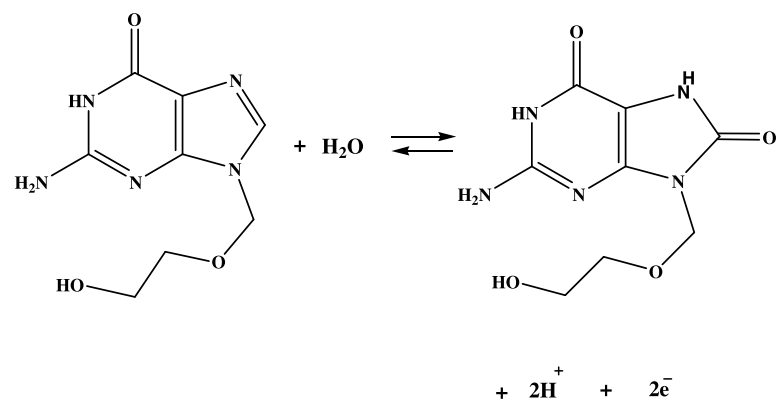

Fig. 5 Oxidation of ACV to the corresponding oxoguanine analog.

Here $I_{\mathrm{p}}$ refers to the peak current, $n$ the number of electron transferred, $A$ the surface area of the electrode, Dr the diffusion coefficient, ${ }^{31} C$ the concentration of $\mathrm{K}_{3} \mathrm{Fe}(\mathrm{CN})_{6}$ and $v$ the scan rate. For $\mathrm{K}_{3} \mathrm{Fe}(\mathrm{CN})_{6}, n=1$ and $\mathrm{Dr}=7.6 \times 10^{-6} \mathrm{~cm} \mathrm{~s}^{-1}$. The surface area can be calculated from the slope of the $I_{\mathrm{p}}$ versus $v^{1 / 2}$. The surface area for a bare electrode was found to be $1.005 \mathrm{~cm}^{2}$. On modification with MBZ/TMHPP $\mathrm{Cu}(\mathrm{II})$ the effective surface area was increased to $3.015 \mathrm{~cm}^{2}$, i.e., there is a threefold increase in surface area. This is strong evidence for the successful and effective modification of GE using MBZ/TMHPP Cu(II).

Further evidence for the modification of GE was obtained from the surface morphology studies using a scanning electron microscope (SEM). SEM images of both bare GE, MBZ modified GE and MBZ/TMHPP Cu(II)-modified GE are shown in Fig. 4. The SEM image of MBZ-modified GE showed that SAM was formed on the surface of GE and that of MBZ/TMHPP $\mathrm{Cu}$ (II)-modified GE showed that the SAM-modified electrode surface contains layers of TMHPP $\mathrm{Cu}(\mathrm{II})$.

\section{Electrochemical behavior of MBZ/TMHPP Cu(II)-modified GE}

The electrochemical behavior of ACV at MBZ/TMHPP $\mathrm{Cu}(\mathrm{II})$ modified GE has been investigated using CV and SWV. The anodic current generated for the ACV electrooxidation process may be due to the oxidation of one electro reactive functional group in multiple steps or simultaneous oxidation of electro reactive functional groups present in the ACV structure. Herein, one oxidation peak is obtained; this is attributed to the two electron oxidation of $\mathrm{ACV}$ to the corresponding oxoguanine analog according to the mechanism ${ }^{32}$ shown in Fig. 5.

Figures 6 and 7 represent cyclic voltammograms obtained 


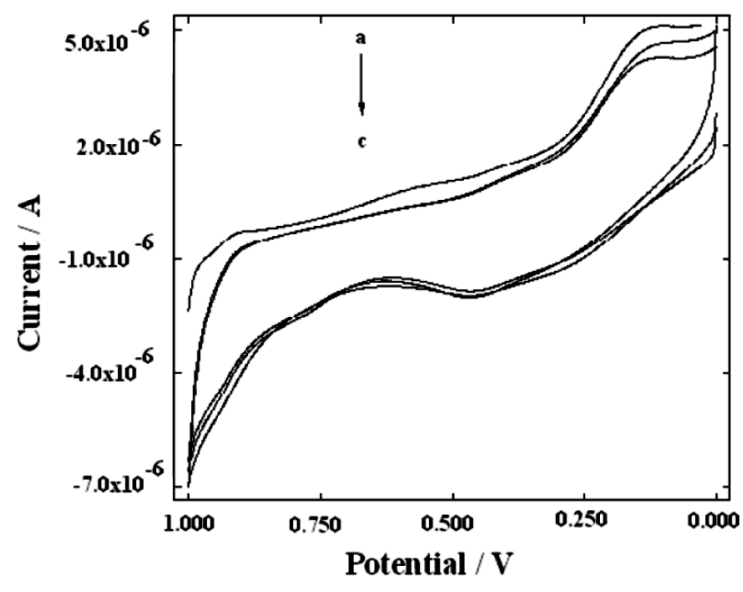

Fig. 6 Cyclic voltammograms of (a) bare GE, (b) MBZ-modified $\mathrm{GE}$, (c) MBZ/TMHPP Cu(II)-modified GE in PBS (pH 7) solution.

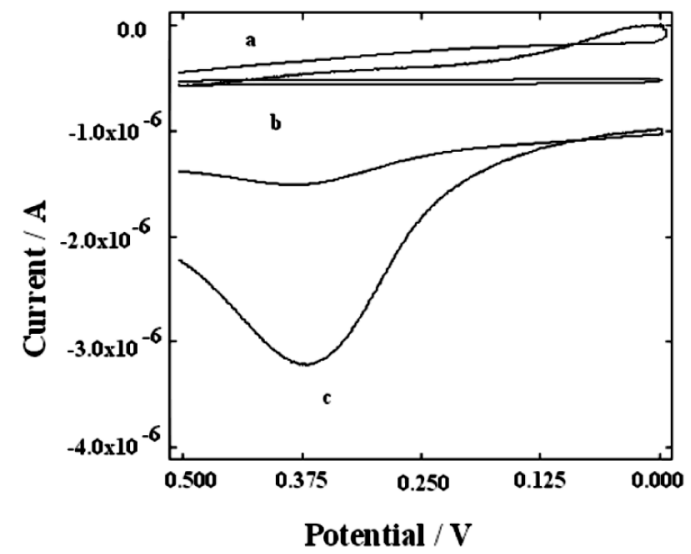

Fig. 7 Cyclic voltammograms of (a) bare GE, (b) MBZ-modified GE, (c) MBZ/TMHPP $\mathrm{Cu}$ (II)-modified $\mathrm{GE}$ in $\mathrm{ACV}\left(1 \times 10^{-3} \mathrm{M}\right)$ solution.

using bare GE, MBZ-modified GE and MBZ/TMHPP $\mathrm{Cu}$ (II)-modified GE in PBS ( $\mathrm{pH} 7$ ) alone and in ACV solution. No response was found in PBS ( $\mathrm{pH} 7$ ) or in ACV solution for bare GE, as well as in MBZ-modified GE. MBZ/TMHPP $\mathrm{Cu}(\mathrm{II})$-modified GE gave no response in PBS ( $\mathrm{pH}$ 7) solution. But on addition of $1 \times 10^{-3} \mathrm{M}$ ACV solution, an oxidation peak at $0.36 \mathrm{~V}$ was obtained. The electrochemical behavior of ACV shows that MBZ/TMHPP $\mathrm{Cu}(\mathrm{II})$-modified GE exhibits electrocatalytic activity to the oxidation of ACV. No reduction peak is observed for ACV in the reverse sweep of $\mathrm{CV}$, indicating an irreversible electrochemical process.

Figure 8 displays the comparison of square wave voltammograms of $1 \times 10^{-3} \mathrm{M} \mathrm{ACV}$ in PBS ( $\mathrm{pH} 7$ ) at bare GE, MBZ-modified GE and MBZ/TMHPP Cu(II)-modified GE. At bare GE, ACV exhibits no voltammetric response. Also, ACV does not generate a voltammetric peak on MBZ-modified GE. Under the same conditions, a well defined and sensitive oxidation peak appears at $0.22 \mathrm{~V}$ for the MBZ/TMHPP $\mathrm{Cu}(\mathrm{II})$-modified GE. Compared to cyclic voltammetric technique, this square wave voltammetric technique was found to be more sensitive for ACV determination. A very low detection limit of the order of $1 \times 10^{-8} \mathrm{M}$ was obtained by using the square wave voltammetric technique. So this square wave voltammetric technique was used for further studies.

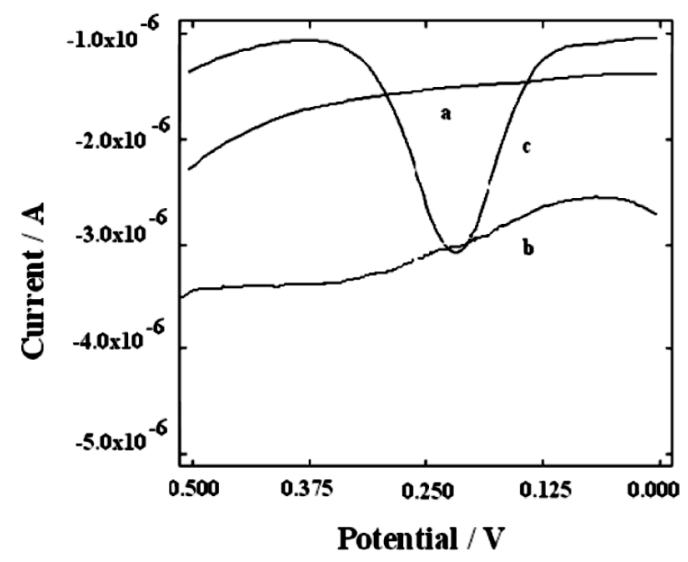

Fig. 8 Square wave voltammograms of ACV at (a) bare GE, (b) MBZ-modified GE, (c) MBZ/TMHPP Cu(II)-modified GE.
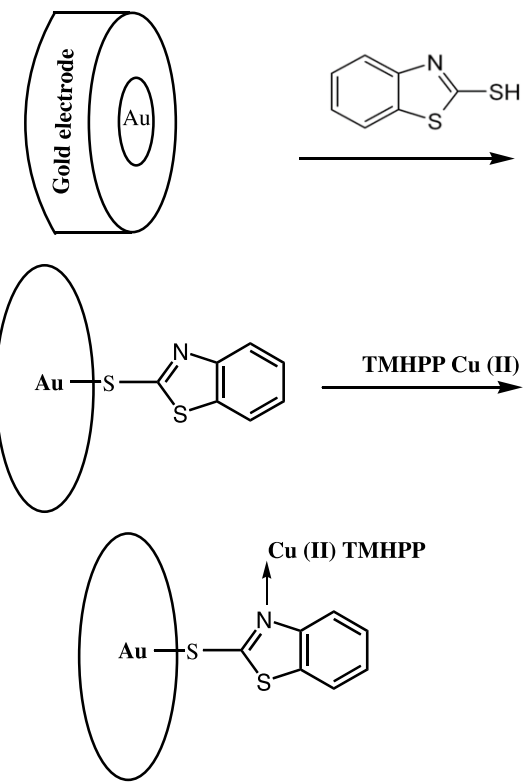

Fig. 9 Schematic representation for the immobilization of TMHPP $\mathrm{Cu}(\mathrm{II})$ on the MBZ-modified GE surface.

Formation and performance of MBZ/TMHPP Cu(II)-modified $G E$

Figure 9 shows the proposed scheme for the immobilization of TMHPP $\mathrm{Cu}(\mathrm{II})$ on the MBZ-modified GE surface. Initially, the surface of the gold electrode was chemically modified with MBZ to form ordered molecular assemblies. By strong S-Au covalent bonds the MBZ molecules were linked to the gold electrode surface. Subsequently, TMHPP $\mathrm{Cu}(\mathrm{II})$ was immobilized on the MBZ monolayer through chemisorption. The $\mathrm{Cu}(\mathrm{II})$ complex coordinates with the nitrogen present in MBZ. MBZ/TMHPP Cu(II) catalyzes the oxidation of ACV to the corresponding oxoguanine analog. The structure of MBZ/TMHPP $\mathrm{Cu}(\mathrm{II})$ is shown in Fig. 10.

\section{Effect of $p H$}

The effects of $\mathrm{pH}$ on the proposed sensor responses were investigated over the $\mathrm{pH}$ range of $3-10$ in PBS containing an ACV concentration of $1 \times 10^{-3} \mathrm{M}$. The anodic current increased up to a value of $\mathrm{pH} 7$, and decreased gradually after that 


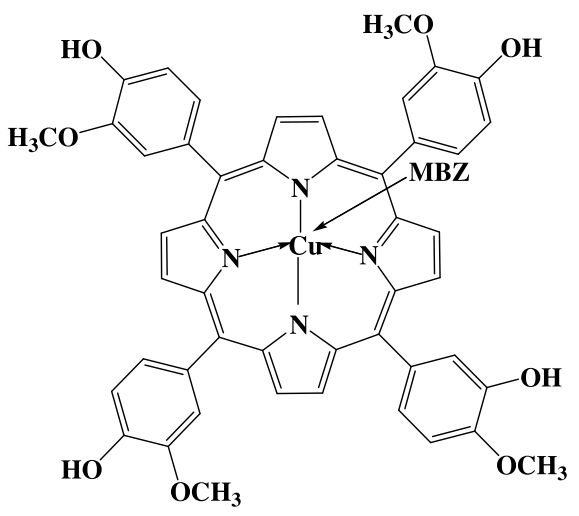<smiles></smiles>

Fig. 10 Structure of MBZ/TMHPP Cu(II).

Table 1 Effect of $\mathrm{pH}$

\begin{tabular}{rl}
\hline $\mathrm{pH}$ & Current/A \\
\hline 3 & $2.51 \times 10^{-6}$ \\
4 & $2.63 \times 10^{-6}$ \\
5 & $2.74 \times 10^{-6}$ \\
6 & $2.90 \times 10^{-6}$ \\
7 & $3.00 \times 10^{-6}$ \\
8 & $2.87 \times 10^{-6}$ \\
9 & $2.72 \times 10^{-6}$ \\
10 & $2.71 \times 10^{-6}$ \\
\hline
\end{tabular}

(Table 1). Thus, pH 7 was selected for the subsequent experiments.

\section{Effect of scan rate}

The effect of scan rate on the electrochemistry of ACV at the MBZ/TMHPP $\mathrm{Cu}$ (II) film-modified GE was investigated by SWV. It was found that the oxidation peak current of $1 \times 10^{-3} \mathrm{M}$ $\mathrm{ACV}$ increases with increase in scan rate in the range of $10-150 \mathrm{mV} \mathrm{s}^{-1}$. The oxidation peak current varies linearly with the square root of scan rate (Fig. 11), indicating that the oxidation of $\mathrm{ACV}$ at the MBZ/TMHPP $\mathrm{Cu}$ (II)-modified GE is diffusion-controlled.

\section{Calibration curve}

The relationship between the anodic peak current of ACV and its concentration was investigated by SWV. The oxidation peak current was found to increase with increase in the concentration. A linear response was found to obtain from $1 \times 10^{-3} \mathrm{M}-$ $1 \times 10^{-8} \mathrm{M}$ with a detection limit of $1 \times 10^{-8} \mathrm{M}$.

\section{Interference study}

In order to investigate the selectivity of the method, we have evaluated the interference effects of some biologically important compounds on the electrochemical oxidation of $1 \times 10^{-3} \mathrm{M}$ ACV. The results are given in Table 2. It was found that $1 \times 10^{-1} \mathrm{M}$ glycine, sodium chloride, potassium chloride, glucose, urea, uric acid, acetic acid, sodium lauryl sulfate,

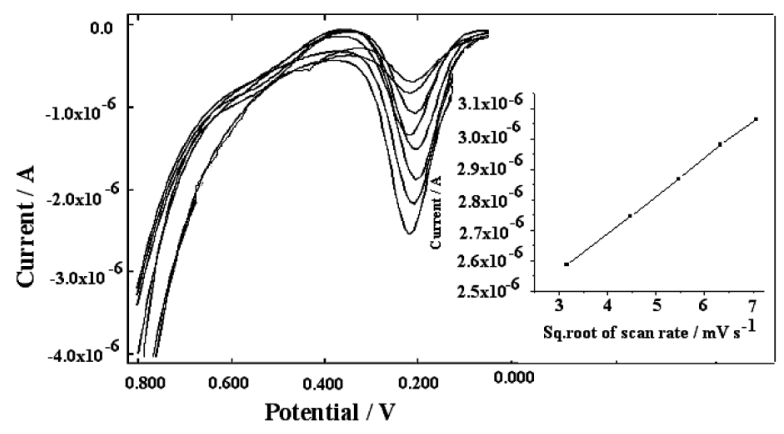

Fig. 11 Overlays of square wave voltammograms of ACV at MBZ/TMHPP $\mathrm{Cu}$ (II) in $0.1 \mathrm{M}$ PBS (pH 7) containing $1 \times 10^{-3} \mathrm{M}$ $\mathrm{ACV}$ at different scan rates. Inset is the plot of current versus square root of scan rate.

Table 2 Interference study

\begin{tabular}{lcc}
\hline \multicolumn{1}{c}{ Interferent } & Concentration/M & Signal change, $\%$ \\
\hline Glycine & $1 \times 10^{-1}$ & 2.05 \\
Sodium chloride & $1 \times 10^{-1}$ & 2.00 \\
Potassium chloride & $1 \times 10^{-1}$ & 2.09 \\
Glucose & $1 \times 10^{-1}$ & 2.10 \\
Lactose & $1 \times 10^{-1}$ & 2.13 \\
Urea & $1 \times 10^{-1}$ & 1.99 \\
Uric acid & $1 \times 10^{-1}$ & 2.00 \\
Acetic acid & $1 \times 10^{-1}$ & 2.53 \\
Dopamine & $1 \times 10^{-1}$ & 2.34 \\
Sodium lauryl sulfate & $1 \times 10^{-1}$ & 1.80 \\
Magnesium stearate & $1 \times 10^{-1}$ & 2.44 \\
Guanine & $1 \times 10^{-1}$ & 30.0 \\
Ascorbic acid & $1 \times 10^{-1}$ & 22.4 \\
\hline
\end{tabular}

magnesium stearate and dopamine have almost no influence on the current response of $1 \times 10^{-3} \mathrm{M} \mathrm{ACV}$ (signal change below $5 \%$ ). However, ascorbic acid and guanine interfere severely with the oxidation signal of ACV.

\section{Stability of MBZ/TMHPP Cu(II)-modified GE}

The stability of MBZ/TMHPP $\mathrm{Cu}(\mathrm{II})$-modified GE was investigated by measuring the voltammetric response of $1.0 \times 10^{-3} \mathrm{M} \mathrm{ACV}$ in $0.1 \mathrm{M}$ PBS ( $\mathrm{pH} 7.0$ ) every day over 4 weeks. The results showed that there was an apparent loss of activity after 18 days. Such stability can be attributed to the high level orientation of MBZ/TMHPP $\mathrm{Cu}$ (II) on GE.

Determination of ACV in pharmaceutical formulation (tablet)

The high sensitivity and wide concentration range of the proposed method made it available for the determination of ACV in pharmaceutical formulations. Ten tablets were weighed, crushed and ground into fine powder. An adequate amount of this powder, corresponding to the concentration $1 \times 10^{-5} \mathrm{M}$, was taken, dissolved in dilute methanol and filtered into a $100-\mathrm{ml}$ titrimetric flask and the material was made up to volume. Solutions of different concentrations were prepared by serial dilution of the stock with PBS (pH 7). SWV was recorded and the unknown concentrations were determined from the calibration graph. The results shown in Table 3 are in good agreement with the declared ACV content and showed a high degree of precision. 
Table 3 Determination of ACV in tablet

\begin{tabular}{|c|c|c|c|c|}
\hline Sample & $\begin{array}{c}\text { Declared } \\
\text { amt./mg } \\
\text { tablet }^{-1}\end{array}$ & $\begin{array}{l}\text { Found }{ }^{\mathrm{a}} \\
\text { mg } \\
\text { tablet }^{-1}\end{array}$ & $\begin{array}{c}\text { Standard } \\
\text { deviation }^{\mathrm{a}}\end{array}$ & $\begin{array}{l}\text { Coefficient } \\
\text { of variance }{ }^{\mathrm{a}}\end{array}$ \\
\hline Acivir (Cipla, India) & 400 & 399 & 4.65 & 1.17 \\
\hline $\begin{array}{l}\text { Zovirax (Burroughs } \\
\text { wellcome India) }\end{array}$ & 200 & 198 & 4.94 & 2.49 \\
\hline
\end{tabular}

a. Average of six replicates.

Table 4 Determination of ACV in urine samples

\begin{tabular}{ccc}
\hline Added/M & Found/M & Recovery, \% \\
\hline $3.00 \times 10^{-6}$ & $3.07 \times 10^{-6}$ & 102 \\
$8.00 \times 10^{-6}$ & $8.02 \times 10^{-6}$ & 100 \\
$2.00 \times 10^{-7}$ & $2.02 \times 10^{-7}$ & 101 \\
\hline
\end{tabular}

\section{Determination of ACV in urine sample}

The developed sensor was applied for the determination of $\mathrm{ACV}$ in urine samples. Urine samples of $5 \mathrm{ml}$ were taken in different $25 \mathrm{ml}$ standard flasks. An adequate amount of ACV corresponding to $1 \times 10^{-3} \mathrm{M}$ was added to each urine sample. This solution was quantitatively diluted using PBS to obtain various concentrations. The prepared solution was analyzed for ACV using MBZ/TMHPP Cu(II)-modified GE by SWV method and the unknown concentrations were determined from the calibration graph. The results are shown in Table 4. The Coefficient of variance of six replicates shows that the results are reproducible.

\section{Conclusions}

TMHPP $\mathrm{Cu}$ (II) was immobilized on MBZ-modified GE to construct a novel sensor for the determination of ACV. In the presence of TMHPP $\mathrm{Cu}(\mathrm{II})$, the electrode area enlarged and the blocking action of MBZ disappeared. ACV generates one anodic peak at $0.22 \mathrm{~V}$ in $0.1 \mathrm{M}$ PBS ( $\mathrm{pH} 7$ ). The developed method can reduce the applied potential for the oxidation of ACV. The simplicity, sensitivity and low analytical cost demonstrate its analytical utility as a sensor for the determination of ACV.

\section{Acknowledgements}

The authors are grateful to the Defence Research and Development Organisation (DRDO), India for the financial assistance in the form of project, IIT Chennai, India and to Sophisticated Test and Instrumentation Centre (STIC), Cochin University, India for providing all help for the analysis of compounds.

\section{References}

1. H. Heli, M. Zarghan, A. Jabbari, A. Parsaei, and A. A.
Moosavi-Movahedi, J. Solid State Electrochem., 2010, 14, 787.

2. R. Boulieu, C. Gallant, and N. Silberstein, J. Chromatogr., B, 1997, 693, 233.

3. S. M. Tadepalli, R. P. Quinn, and D. R. Averett, Antimicrob. Agents Chemother., 1986, 29, 93.

4. K. M. Skubitz, R. P. Quinn, and P. S. Lietman, Antimicrob. Agents Chemother., 1982, 21, 352.

5. A. D. Ibrahim, S. K. Alaa, F. A. Hassan, and M. M. Ramadan, J. I. Farmaco, 2005, 60, 555.

6. Y. H. Liu, O. Sha, and G. F. Wang, J. Huaihai Institute of Technology, 2005, 2, 56.

7. C. V. Hung, A. H. Paul, T. L. Daniel, and L. S. Stephen, J. Chromatogr., B, 2002, 772, 291.

8. J. G. Lv, L. R. Luo, and Z. J. Zhang, Anal. Chim. Acta, 2004, 510, 35 .

9. J. Obirai and T. Nyokong, Electrochim. Acta, 2004, 49, 1417.

10. I. Zilbermann, J. Hayon, T. Katchalski, R. Ydgar, J. Rishpon, A. I. Shames, E. Korin, and A. Bettlelheim, Inorg. Chim. Acta, 2000, 305, 53.

11. C. A. Caro, F. Bedioui, and J. H. Zagal, Electrochim. Acta, 2002, 47, 1489.

12. M. J. Cook, J. Mater. Chem., 1996, 6, 677.

13. B. M. Hassan, H. Li, and N. B. Mckeown, J. Mater. Chem., 2000, 10, 39.

14. M. J. Cook, Pure Appl. Chem., 1999, 71, 2145.

15. H. O. Finklea, "Electroanalytical Chemistry", ed. A. J. Bard and I. Rubinstein, 1996, Vol. 19, Marcel Dekker, New York, 109.

16. H. O. Finklea, "Encyclopaedia of Analytical Chemistry: Applications, Theory and Instrumentations", ed. R. A. Meyers, 2000, Vol. 11, Wiley, Chichester, 10090.

17. I. Turyan and D. Mandler, Anal. Chem., 1997, 69, 894.

18. A. S. N. Murthy and J. Sharma, Anal. Chim. Acta, 1998, $363,215$.

19. B. Ge and B. Lisdat, Anal. Chim. Acta, 2002, 454, 53.

20. R. Joseph and K. G. Kumar, Anal. Lett., 2009, 42, 2309.

21. L. Rajith and K. G. Kumar, Drug Test Analysis, 2010, 2, 436.

22. A. M. C. Martins, J. P. Dodelet, D. Guay, M. Ladouceur, and G. Tourillon, J. Phys. Chem., 1992, 96, 10898.

23. S. Wang, D. Du, and X. Xu, J. Appl. Electrochem., 2004, 34,495

24. B. Agboola, P. Westbroek, K. I. Ozoemena, and T. Nyokong, Electrochem. Commun., 2007, 9, 310.

25. B. Agboola and T. Nyokong, Talanta, 2007, 72, 691.

26. F. Matemadombo and T. Nyokong, Electrochim. Acta, 2007, 52, 6856.

27. B. Agboola, K. I. Ozoemena, P. Westbroek, and T. Nyokong, Electrochim. Acta, 2007, 52, 2520.

28. K. I. Ozoemena, T. Nyokong, D. Nkosi, I. Chambrier, and M. J. Cook, Electrochim. Acta, 2007, 52, 4132.

29. A. D. Alder, F. R. Lonyo, and J. D. Finarelli, J. Org. Chem., 1967, 32, 476.

30. J. E. B. Randles, Trans. Faraday Soc., 1948, 44, 322.

31. L. S. Duan, F. Xie, F. Zhou, and S. F. Wang, Anal. Lett., 2007, 40, 2653.

32. H. Heli, M. Zarghan, A. Jabbari, A. Parsaei, and A. M. Movahedi, J. Solid State Electrochem., 2010, 14, 787. 